\title{
Industrial Agglomeration, Foreign Direct Investment and Green Total Factor Productivity—Evidence from Manufacturing Industries in Chongqing, China
}

\author{
Guohua Yu ${ }^{1}$, Shuqin Xu ${ }^{2, *}$ \\ ${ }^{1}$ School of Economics and Management, Southwest University, Chongqing 400715, China; swuyuecono@163.com \\ (G. Y.); shuqinxu2015@163.com (S.X.) \\ * Correspondence: shuqinxu2015@163.com; Tel.: +86-157-2302-9878
}

\begin{abstract}
This paper studies the influence mechanism of industrial agglomeration and foreign direct investment (FDI) on green total factor productivity (GTFP). We use the SBM Directional Distance Function to measure the GTFP of Chongqing's manufacturing industry from 1999 to 2015. The results show that the level of GTFP in Chongqing's manufacturing industry is relatively low, which is contrary to the current green development mode. By clarifying the conduction path of industrial agglomeration and FDI on GTFP, we use the panel Tobit model to study the effect of industrial agglomeration and FDI on GTFP. The main findings are: the higher the level of industrial agglomeration, the more beneficial it is to increase GTFP. FDI has an inhibitory effect on GTFP. The spillover effect of FDI on GTFP is not significant. At the same time, FDI counteracts the role of industrial agglomeration in promoting GTFP. The findings in a present study indicate that, according to Chongqing's experience, the "pollution haven" is established. Therefore, relying solely on foreign technology to promote the development of the manufacturing industry has many drawbacks clearly. Only by improving the ability of independent innovation is the reliable way to enhance GTFP effectively.
\end{abstract}

Keywords: industrial agglomeration; FDI; green total factor productivity; spillover effect

\section{Introduction}

For a long time, China's manufacturing industry plays an invaluable role in the process of economic growth. As a core component of the developed sector, manufacturing has not only laid a solid progressive foundation and material security, but also provided great momentum for the growth and development of the national economy. However, with the rapid development of the industrial economy and the vigorous promotion of urbanization, many scholars believe that the strong growth of China's manufacturing industry has the problem of "high energy consumption, high pollution, and low efficiency". This extensive industrial growth mode has led to a large amount of resource consumption and serious environmental pollution, and has even approached the limit of the environment. Given China's relatively lax environmental policy, it has raised concerns among academics about whether the developing countries that led by China have become a "pollution haven" for multinational companies (MNCs) [1]. Therefore, under the background of increasing environmental pollution, tightening of resource constraints, and economic restructuring, green development has become the only way to break the constraints of resources and the environment that a country faces in its development and achieves sustainable development. In recent years, Chongqing's economic growth performance has been eye-catching. Changing's economic growth has largely depended on the development of the manufacturing industry. However, most of Chongqing's manufacturing industry are dominated by extensive industries. The productions of environmental protection technologies and energy use efficiency are low. The full energy consumptions per unit of GDP and whole amount of carbon dioxide emissions are high. The manufacturing industry is increasingly polluting the environment and caused by the manufacturing industry. Industrial 
pollution is difficult to eliminate in the short term. Therefore, if we want to realize the growth of manufacturing from "extensive" to "intensive", the key is to improve the green total factor productivity (GTFP) ${ }^{1}$ [2] of manufacturing industry. This means that studying the GTFP of Chongqing's manufacturing industry, and its influencing factors will play an important role in promoting sustainable economic growth in Chongqing.

At present, there is relatively little research on the green total factor productivity of the manufacturing industry in the academia. Most studies focus on two aspects: industrial agglomeration and foreign direct investment on the total factor productivity of manufacturing. As an important form of spatial organization, whether industrial agglomeration can achieve technological innovation and technological progress has always been the focus of attention of all scholars. On the one hand, some studies have confirmed that industrial agglomeration has a positive effect on the productivity of manufacturing enterprises [3, 4]. There are two mechanisms behind this conclusion: firstly, the agglomeration area can provide the basic elements for innovation, such as labor, production mode and so on. Secondly, the agglomeration area can provide innovative environment, which is beneficial to innovation knowledge and technology spillover effect [5,6]. On the other hand, in the process of industrial agglomeration, "crowding effects" and "free-rider problem" are more likely to occur, and the innovation power of enterprises is insufficient. When the level of industrial agglomeration exceeds the limits that cities can afford, it will lead to resource congestion and environmental pollution. Other negative external effects, lead to a decrease in the efficiency of manufacturing and even the entire production system [7]. Secondly, the impact of foreign direct investment on total factor productivity of manufacturing industry. As we all know, technological progress is the source of economic development and inexhaustible motive force. Technological progress requires increased investment and the introduction of advanced technologies. Clearly foreign capital plays an important role in improving technological progress. In particular, for developing countries, if they rely solely on increasing input and rising technological progress from independent research and development, it will take a lot of capital and a lot of time to reach the level of developed countries. Therefore, in order to narrow the technological gap with developed countries in a short time, many developing countries hope to introduce advanced technology with foreign capital. It is generally believed that developing countries reverse the situation that lacking of technological innovation in primary stage of development through utilizing the technology spillover effect of FDI [8]. The impact of FDI on total factor productivity mainly comes from "competition effects" and "spillover effects"2 [9]. The inflow of FDI can exacerbate competition and create a selection mechanism for survival of the fittest by squeezing the market share of domestic companies [10]. Competition effects will enable the host country to carry out technological innovation and improve the efficiency of resource allocation. Zhao (2010) based on the data of foreign direct investment of some developed countries in China from 1991 to 2007, using the vector autoregressive models for empirical analysis. The study found that China obtained a clear technology spillover effect from foreign direct investment, which led to a significant increase in total factor productivity [11]. Hiau (2014), when studying the FDI in the host country Bangladesh, found that FDI can not only promote the host country's technological progress, but also help the home country investment enterprises expand the product range and increase the internal production efficiency [12]. However, some scholars believe that FDI has promoted a country's rapid economic growth and has also led to serious "trade induced type" environmental pollution [13]. Because of the weak environmental regulation in developing countries, in order to reduce the cost of pollution

${ }^{1}$ When measuring the TFP of the swedish pulp mill, Chung et al.(1997) introduces a directional distance function that considers both expected output increase and undesired output reduction, which can be regarded as undesired output to measure green total factor productivity.

${ }^{2}$ Blomström(1998) defines the FDI spillover effect as taking place when the entry or presence of MNC affiliates lead to productivity or efficiency benefits in the host country's local firms, and the MNCs' are not able to internalize the full value of these benefits. 
control, the developed countries transfer the production and processing links of the polluted products or the polluting industries to the developing countries through the form of FDI. Therefore, a scale effect on pollution occurs insofar as the activity of these MNCs contributes significantly to the increase of industrial production in the host country, which consequently results in an overall level of higher pollution $[14,15,16]$.

The existing literature on the study of total factor productivity in manufacturing provides a good reference for understanding the green technological progress of the manufacturing industry. Through the exploration of manufacturing transformation, scholars have gradually realized that the growth of GTFP has played an important role in the development of the manufacturing industry. However, by sorting out the existing literature, this paper believes that there is still the possibility of further perfecting and deepening the research on GTFP of manufacturing industry, which can be summarized as the following three points: (i) With the increasingly serious problems of resources and environment, the constraint on resources and environment for economic development becomes more and more obvious. The "high input, high consumption, and low output" growth mode is not advisable for maintaining sustainable economic development. This shows that when studying the total factor productivity of the manufacturing industry, it is necessary to incorporate environmental factors into the calculation of manufacturing industry performance. In addition, due to the great differences in the level of economic development, the strength of foreign capital utilization, and the conservation of resources and environmental protection in various regions of China, the manufacturing methods in different regions are different. Therefore, it is necessary to investigate the issue of GTFP of the individual provinces in China. (ii) From the perspective of environmental regulation, there is a deficiency in the impact of FDI on GTFP. This is because there is no necessary link between foreign capital and pollution transfer. FDI is not only an international exchange of assets, but also includes the transfer of capital, management, and new technologies. FDI also has a "spillover effect" for the host country. Therefore, by examining the actual situation in China, this article will elaborate the impact of the two on GTFP of the manufacturing industry from the perspective of industrial agglomeration and FDI. We will elaborate on the second part of the paper. (iii) From the empirical method of TFP of manufacturing industry, scholars generally adopt the method of random frontier production function or directional distance function in the process of research, select one or several kinds of environmental pollutants to join the productivity analysis framework, and analyze the total factor productivity of manufacturing industry under the constraints of resource and environment by empirical analysis. Because of the differences in the empirical methods and the choices of variables, scholars' conclusions and viewpoints are different. Because this article regards Chongqing as the research object, this needs to abandon the intrinsic research conclusion.

In an attempt to fill in these gaps, This article takes Chongqing as the starting point, and analyzes the influence mechanism of the two on GFTP of manufacturing industry based on industrial agglomeration and FDI. On this basis, we use SBM Directional Distance Function to measure the GTFP of Chongqing's manufacturing industry, and then use the panel Tobit model to study the impact of industrial agglomeration and FDI on GTFP.

The paper is organized as follows. In Section 2, we elaborate the impact of industrial agglomeration and FDI on the GTFP of manufacturing industry. Section 3 introduces the measure of the manufacturing green total factor productivity and calculates the GTFP of manufacturing industry in Chongqing, China. Section 4 is the model design and data description. In Section 5, we present and discuss the empirical results. The last section summarizes and concludes the paper.

\section{Theoretical Mechanism}

Industrial agglomeration is the spatial organization form of division of labor. It is an intermediate organization between market and enterprise, and has dual advantages of market and enterprise. The result of the agglomeration of manufacturing enterprises is to form a close-knit group that is both competitive and 
cooperative, so that enterprises, suppliers and related service organizations engaged in the productions of a certain product type are concentrated in a certain geographical area. Through the interrelated industries, the system can interact in the capital, labor division and technological innovation, and continuously strengthen the "combined effect" of the manufacturing industry, thus providing a good external environment for improving the efficiency of the manufacturing industry. The influence of industrial agglomeration on the GTFP of the manufacturing industry is mainly reflected in three aspects: First, the agglomeration area has enhanced the specialization level of the manufacturing industry. After the enterprises of the same industry gather in a region, the mutual exchange of learning between enterprises will result in spillovers of knowledge, and the existing level of technology and management will be continuously improved, so that the level of specialization in production within the cluster will be improved, which will help to improve the progress of technology and the efficiency of energy use. Secondly, the agglomeration area will attract a large number of professional talents to inflow, which will help the flow of silent knowledge between enterprises, accelerate the knowledge spillover effect of manufacturing technology, and enhance the ability of the company to digest and absorb technology. This is because professionals can more easily cope with the market's demand for cleaning products and green products, and are more capable of carrying out green environmental protection technology innovation and research. Third, enterprises in the cluster can share infrastructure and reduce production costs. After multiple types of enterprises are clustered in a region, the government will implement the construction of public infrastructure in the agglomeration area for economic growth. Enterprises in the agglomeration can use these infrastructures to reduce the extra cost of production and increase the profitability of the company. At the same time, in order to enhance their market competitiveness, manufacturing enterprises will invest more idle funds into environmental technology innovation and clean product research and development, thereby increasing GTFP.

However, the impact of industrial agglomeration on GTFP also follows the law of diminishing marginal effect, and excessive gathering causes "crowding effect", such as pollution concentration, land price rise, malignant competition and so on, which hinders the improvement of GTFP. This is mainly reflected in three aspects: firstly, the excessive consumptions of resources and environmental pollution in the agglomeration area are serious. In the process of product production, enterprises must give priority to the use of resources in the agglomeration area, and there are many enterprises in the agglomeration area to use the resources. If there is no strict constraint, it will inevitably cause the excessive consumption of resources in the region. At the same time, the environment of the agglomeration area is a kind of public resource, and the enterprises hold an irresponsible attitude and do not bear the psychological cost. Their production behavior will cause pollution and damage to the environment, thus reducing the green total factor productivity. Secondly, the ability of independent innovation of enterprises is decreasing. Because of of the spillover effect of gathering knowledge and technology, enterprises usually take "free-rider problem" to reduce the cost of R\&D, so that the innovation results or technology of one enterprise is easily imitated by other enterprises. The protection system of intellectual property rights in China is not perfect enough. It further reduces the motivation of enterprise innovation. Third, the agglomeration area is easy to cause excessive competition. With the increasing number of enterprises in the agglomeration area, the products produced will continue to increase, but the demand of the market is inelastic. When the supply is greater than the demand, it will lead to excessive competition, that is, the large enterprises have reduced the product price, which leads to the decrease of profit and the decrease of profit will lead to the enterprises to reduce the scientific research. The technological innovation capability of enterprises will stagnate. At the same time, some companies do not have enough funds to carry out technological innovation. To maintain the development of the enterprise, they can only obtain regular public management resources and the public environment to achieve normal operations. This will further damage the ecological environment and will not be conducive to the improvement of GTFP. Based on this, we put forward 
the hypothesis:

Hypothesis 1: The impact of industrial agglomeration on the GTFP depends on combined effect and crowding effect. The appropriate industrial agglomeration is conducive to the improvement of GTFP, excessive industrial agglomeration will hinder the improvement of GTFP.

At present, with the deepening of China's opening up, the opportunities for manufacturing enterprises to trade with other countries are also increasing. Foreign direct investment has played an important role in promoting economic development, and also has a profound impact on the green total factor productivity of manufacturing industry. Before analyzing the mechanism of FDI on GTFP, we discuss how industrial agglomeration effectively attracts foreign direct investment. Firstly, in the industrial agglomeration area, because of the similar enterprise, cultural background and the close geographical position make a recessive psychological contract between enterprises. The existence of an industrial division of labor among the enterprises also allows a trust between each other. As a result, the company's transaction in the industrial agglomeration area has increased its credibility and broke the trade barriers among the enterprises. Secondly, foreign investment should take into account the factors of information, because the timely acquisition of information is an important influence factor for enterprises to obtain competitive advantage. The enterprises in the agglomeration area are close to the geographical position. The exchange of information in the market is more frequent. The information can be quickly spread and shared, which greatly reduces the formation of the search information. This reduces the vicious competition between enterprises due to asymmetric information, or the cost of transaction default. Finally, there are perfect infrastructure and professional services in the agglomeration area, and the public infrastructure can be used jointly among enterprises, which reduces the extra cost investment of foreign enterprises. Therefore, there is a certain correlation between industrial agglomeration and FDI, and industrial agglomeration is conducive to attracting FDI. The mechanism of FDI effect on GTFP is mainly reflected in: Firstly, FDI has a competitive effect. Generally speaking, multinational corporations are advanced in technology, while host enterprises are relatively low in technology. In the technological innovation and spillover mechanism of industrial agglomeration, multinational corporations play a key role. Through export-oriented and innovative learning, the advanced knowledge is obtained from the external cluster, and technological innovation and spillover are carried out to promote the technological progress of the host country. Meanwhile, intensified competition among enterprises in the industrial agglomeration area will stimulate manufacturing enterprises to increase production efficiency. The reason is that, if the manufacturing enterprises with low productivity are unable to reduce the cost and improve the quality of service products in the fierce market competition, they will be forced to withdraw from the industry, which leads to the reconfiguration of resources to higher productivity service enterprises, which makes the technological level of the manufacturing enterprises in the cluster improve. Secondly, FDI has spillover effect. The improvement in productivity also leads to an increase in external competitiveness and attracts FDI. A country can attract foreign direct investment through industrial agglomeration. Through "learning by doing" effect, manufacturing enterprises can digest and absorb advanced technical and management concept of foreign countries, effectively increase the knowledge reserve. The accumulated knowledge and technology can be used in the daily production activities of enterprises and improve the production technology of enterprises. At the same time, the same time, it encourages enterprises to establish green development consciousness. On the one hand, with the deepening of the manufacturing industry agglomeration, the multinational enterprises will continue to enter the local market. The local enterprises will face the competitive pressure from the high-quality products or services from abroad. However, the manufacturing enterprises can also raise the level of the science and technology of the industry by imitating and absorbing, and create more competitive products of the same kind. On the other hand, when multinational corporations enter a country's market to invest, in order to better adapt to the local market environment, they usually choose to hire local staff, and fewer choose to hire professional staff from their own 
country. This is undoubtedly one of the best ways to familiarize themselves with the local culture. Multinational corporations usually train the employed management and technical personnel so that they can disseminate the knowledge and experience accumulated by multinational corporations to the host country's enterprises, thereby creating a spillover effect of knowledge and technology. At the same time, the relationship between domestic enterprises and foreign enterprises will be based on the industrial chain, which will enable the technology of foreign enterprises to spread. The advanced technology can effectively improve the efficiency of energy use, so that the green production efficiency of a country's manufacturing enterprises will be achieved.

However, there are differences in environmental protection policies among countries, developing countries with low environmental regulation standards have strong attraction for FDI. In order to reduce the cost of pollution control, multinational manufacturing companies tend to shift the more polluting industries to developing countries with low environmental regulation standards through FDI, which has a negative impact on the host country environment, namely the "pollution haven" hypothesis. At the same time, in order to expand the scale of output and employment and increase its attraction to foreign investment, the host government may choose not to strengthen or even relax the enforcement of environmental regulation, which is not conducive to the improvement of local environmental regulation standards and the improvement of environmental welfare [17]. The final result is to restrain the increase of the green total factor productivity of the manufacturing industry. Based on this, this article puts forward the hypothesis:

Hypothesis 2: the FDI has a positive and negative impact on GTFP in manufacturing industry, and the positive effect mainly comes from FDI spillover effect. The negative impact mainly comes from pollution haven effect.

\section{The Measure of the Manufacturing Green Total Factor Productivity}

\subsection{Evaluation Index System of Green Total Factor Productivity in Manufacturing Industry}

From the calculation method of GTFP, Chung et al. (1995) uses SBM Directional Distance Function to calculate the TFP containing the undesired output of pollution emission, and the first method are reasonable to fit the influence of the pollution emission to the production efficiency [2]. Chambers et al. (1996) included environmental pollution factors in the assessment of TFP performance, and proposed a behavioral model of environmental regulation based on directional distance functions, measured TFP considering the environment, and promoted the consideration of environmental factors. The study of factor productivity also pushes research on environmental and economic growth to a higher level [18]. Fare et al. (1997) earlier proposed a data envelopment model containing undesired emissions of pollutants. Since then, many scholars have tried to use the environmental pollutants produced by energy consumption as negative externalities, and introduce the expected output into the process of economic production to calculate the TFP [19, 20, 21, 22, 23]. In the following, the evaluation index system of GTFP in the manufacturing industry is first constructed, and then the SBM Directional Distance Function is used to measure the total TFP of the manufacturing industry in Chongqing.

The neoclassical economic growth theory usually considers only two input variables, capital and labor, and output and output variables when measuring total factor productivity. In the process of constructing the evaluation index system, this paper mainly refers to existing studies to select relevant inputs and outputs. In the selection of input indicators, there are mainly three indicators of labor, capital and energy consumption. In the selection of output indicators, the main use of Zofío and Prieto (2001) and Jeon and Sickles (2004), the total industrial output value as expected output and carbon emissions as undesired output[24, 25]. In the past, many studies did not incorporate environmental pollution caused by input factors of the industry into the accounting system when measuring the total factor productivity of the manufacturing industry. The core of improving 
GTFP lies in the input of a fixed amount of industrial production factors and makes production. Elements minimize pollution to the environment and maximize industrial output. Based on this, this paper includes the total carbon emissions from manufacturing industry production as unsatisfactory output of the manufacturing industry into the manufacturing industry output index system. This article's specific input-output index system is shown in Table 1.

Table 1. Evaluation Index System of Green Total Factor Productivity in Manufacturing Industry

\begin{tabular}{ccc}
\hline Index System & Index Type & Index Name (Unit) \\
\hline \multirow{2}{*}{ Inputs } & Labor Input & Labor (10,000 People) \\
& Capital Input & Capital (10,000 Yuan) \\
& Energy Input & Energy (10,000 Tons Standard Coal) \\
\multirow{2}{*}{ Outputs } & Expected Output & Total Industrial Output Value (10,000 Yuan) \\
& Undesired Output & Total Carbon Emissions (10,000 Tons) \\
\hline
\end{tabular}

The above indicators are explained and explained in detail below. Firstly, it is the processing and explanation of the input indicators: (i) Labor. From a broad sense, the selection of labor input indicators should be considered in theory, such as the number of labor force, the quality of labor, labor time, labor efficiency, and so on. This is because the education degree, labor length, labor intensity and other characteristics of the workers will have a certain impact on industrial output. In the selection process of labor input indicators, most scholars choose the number of workers in the industry to measure. In view of this, this article will choose the average number of employees (10,000 People) in Chongqing's manufacturing industry as the index of labor input. (ii) Capital. This paper mainly uses the sum of current assets and fixed assets in the production process to measure capital input. (iii) Energy. Manufacturing industry is an industry with obvious energy consumption characteristics. The development of the manufacturing industry largely depends on the input of a large amount of energy and resources. Therefore, in this paper, the energy consumption of manufacturing industry in the production process is added to the calculation of input indicators to improve the accuracy of GTFP measurement process. This article mainly uses the total energy consumption of various industries in the manufacturing industry as a measure of its energy consumption, and converts it into 10,000 tons of standard coal according to the standard coal conversion factor. The coefficient of conversion is derived from the appendix of the China Energy Statistical Yearbook in 2000. Secondly, it is the processing and explanation of the output indicators: (i) Total Industrial Output Value. There are still some divergences in the selection of output indicators for most scholars. The more common indicators are industrial net profit and industrial added value. The net profit of industry can not fully reflect the true efficiency of GTFP, because the net profit of industry mainly includes the marketing model of sales revenue and sales cost and so on, and there are many factors that affect the sales revenue and the total profit of the industry. In order to effectively understand the economic scale of the industry, we choose the output value of manufacturing industry as an output index, which is also one of the most widely used research indicators. (ii) Total Carbon Emissions. There is no doubt that manufacturing is an industry with high energy consumption characteristics, and the development of manufacturing industry is largely dependent on a large amount of energy and resource consumption, and environmental pollution in this process. This paper will use the principle of "electrical (thermal) carbon sharing" to measure the carbon emissions from the manufacturing industry in Chongqing. The formula for the total carbon emissions in the manufacturing industry is:

$$
C_{i j}=\sum_{j=1}^{n} \theta_{j} \times E_{i j}
$$

In formula (1), $E_{i j}$ represents the standard statistics of class $j(j=1,2, \cdots, n)$ energy consumption in category $i$ manufacturing. $\theta_{j}$ denotes the carbon emission coefficient of class $j$ energy. The Chongqing Statistical Yearbook divides the energy categories into seven categories: coal, coke, gasoline, kerosene, diesel, 
natural gas and electricity. The specific conversion coefficient and carbon emission coefficient of the seven kinds of energy are shown in Table 2.

Table 2. Seven Kinds of Energy Conversion Coefficient and Carbon Emission Coefficient

\begin{tabular}{cccccccc}
\hline Sectors & Coal & Coke & Gasoline & Kerosene & Diesel & Natural Gas & Electricity \\
\hline Energy Conversion Coefficient & 0.7143 & 0.9714 & 1.4714 & 1.4714 & 1.4571 & 13.3000 & 1.2290 \\
Carbon Emission Coefficient & 0.7476 & 0.1128 & 0.5532 & 0.3416 & 0.5913 & 0.4479 & 2.2132 \\
\hline
\end{tabular}

At the same time, the measurement unit of conversion coefficient is: natural gas is 10,000 tons standard coal/10,000 cubic meters; electricity is 10,000 tons standard coal/10,000 kilowatt hours; the other energy units are 10,000 tons standard coal/10,000 tons; the unit of carbon emission coefficient is 10,000 tons $/ 10,000$ tons standard coal.

\subsection{Based on SBM Directional Distance Function of GTFP in Manufacturing Industry}

The traditional DEA model adopts a radial and angular measurement method, and it is difficult to examine the effect of the "relaxation amount". In response to this problem, Chung et al. (1997) incorporated input and output slack into the objective function to construct a non-radial, non-angled SBM Directional Distance Function [2]. The SBM Directional Distance Function not only solves the inefficiencies brought about by the input slack, but also solves the unintended output problems involved in the production process. In this paper, the SBM Directional Distance Function, including undesired outputs is used to measure the GTFP of Chongqing's manufacturing industry. The basic principle of the SBM Directional Distance Function is:

Assume that each manufacturing industry is regarded as a decision-making unit to construct the frontier of production, and use $N$ input factors $X$ for each industry, $X=\left(x_{1}, x_{2}, \cdots, x_{N}\right) \in R_{N}^{+}$; Produce $M$ desired output factors $Y, Y=\left(y_{1}, y_{2}, \cdots, y_{M}\right) \in R_{M}^{+}$, and $I$ undesired outputs $Z, Z=\left(z_{1}, z_{2}, \cdots, z_{I}\right) \in R_{I}^{+}$. Make the weight of observations for each cross section $\lambda_{k}^{t}$, Data Envelopment Analysis can be used to express the production frontier of non-expected outputs as follows:

$$
P^{t}\left(x^{t}\right)=\left\{\left(y^{t}, z^{t}\right): \sum_{k=1}^{K} \lambda_{k}^{t} y_{k m}^{t} \geq y_{k m}^{t}, \forall m ; \sum_{k=1}^{K} \lambda_{k}^{t} z_{k i}^{t}=z_{k i}^{t}, \forall i ; \sum_{k=1}^{K} \lambda_{k}^{t} X_{k n}^{t} \leq x_{k n}^{t}, \forall n ; \sum_{k=1}^{K} \lambda_{k}^{t}=1, \lambda_{k}^{t} \geq 0, \forall k\right\}
$$

Further, according to Tone (2003) [26], the SBM Directional Distance Function under the energy environment is defined as follows:

$$
\begin{aligned}
& \vec{S}_{v}^{t}\left(x^{t, k^{\prime}}, y^{t, k^{\prime}}, z^{t, k^{\prime}}, g^{x}, g^{y}, g^{b}\right)=\max _{s^{x}, s^{y}, s^{2}} \frac{\frac{1}{N} \sum_{n=1}^{N} \frac{s_{n}^{x}}{g_{n}^{x}}+\frac{1}{M+I}\left[\sum_{m=1}^{M} \frac{s_{m}^{y}}{g_{m}^{y}}+\sum_{i=1}^{I} \frac{s_{i}^{b}}{g_{i}^{b}}\right]}{2} \\
& \text { s.t. } \sum_{k=1}^{K} \lambda_{k}^{t} X_{k n}^{t}+s_{n}^{x}=x_{k^{\prime} n}^{t}, \forall n ; \sum_{k=1}^{K} \lambda_{k}^{t} y_{k m}^{t}-s_{m}^{y}=y_{k^{\prime} m}^{t}, \forall m ; \sum_{k=1}^{K} \lambda_{k}^{t} z_{k i}^{t}+s_{i}^{z}=z_{k^{\prime} i}^{t}, \forall i ; \sum_{k=1}^{K} \lambda_{k}^{t}=1, \lambda_{k}^{t} \geq 0, \forall k \\
& s_{n}^{x} \geq 0, \forall n ; s_{m}^{y} \geq 0, \forall m ; s_{i}^{b} \geq 0, \forall i
\end{aligned}
$$

Among them, $\vec{S}_{v}^{t}$ represents the directional distance function under VRS. If the weight variables are removed and the constraints equal to 1, the directional distance function under the scale of scale return (CRS) is expressed by $\vec{S}_{v}^{t}$. $\left(x^{t, k^{\prime}}, y^{t, k^{\prime}}, z^{t, k^{\prime}}\right),\left(g^{x}, g^{y}, g^{z}\right)$ and $\left(s_{n}^{x}, S_{m}^{y}, s_{i}^{z}\right)$ are input and output vectors, directional vectors and relaxation variables respectively. According to Chambers et al. (1996) [27], the Luenberger productivity index between $t$ and $t+1$ can be expressed as:

$$
\operatorname{LTFP}_{t}^{t+1}=\frac{1}{2}\left\{\left[\vec{S}_{C}^{t}\left(x^{t}, y^{t}, z^{t}, g\right)-\vec{S}_{C}^{t}\left(x^{t+1}, y^{t+1}, z^{t+1}, g\right)\right]+\left[\vec{S}_{C}^{t+1}\left(x^{t}, y^{t}, z^{t}, g\right)-\vec{S}_{C}^{t+1}\left(x^{t+1}, y^{t+1}, z^{t+1}, g\right)\right]\right\}
$$

In the formula (4), the Luenberger productivity index is the GTFP. In order to observe and reflect the change of GTFP in Chongqing's manufacturing industry, this study sets a time span of 1999-2015. At the same time, considering that the data of the Chongqing Statistical Yearbook is mainly based on the price of the year, it leads to the lack of comparability of the data in the process of time change. This paper uses the price index of the gross product to reduce the nominal variable, so as to eliminate the effect of the change of the valence 
lattice. The object of this study is Chongqing's manufacturing state and the Non-state-owned Industrial Enterprises above the scale, and the data are mainly derived from the Chongqing Statistical Yearbook provided by the Chongqing Statistics Bureau. Based on the research data, this paper uses MaxDEA 6.2 to calculate the GTFP of 27 manufacturing industries of Chongqing in 1999-2015. The annual average value is shown as shown in Table 3.

Table 3. Mean Value of Green Total Factor Productivity

\begin{tabular}{|c|c|}
\hline Manufacturing Industry & Mean Value of GTFP \\
\hline Processing of Food from Agricultural Products & 0.7556 \\
\hline Manufacture of Foods & 0.3971 \\
\hline Liquor, Beverage and Refined Tea & 0.3537 \\
\hline Manufacture of Tobacco & 0.8793 \\
\hline Manufacture of Textile & 0.3265 \\
\hline Manufacture of Textile Wearing Apparel, Footware and Caps & 0.5554 \\
\hline Manufacture of Leather, Fur, Feather and Related Products & 0.7619 \\
\hline Processing of Timber, Manufacture of Wood, Bamboo, Rattan, Palm and Straw Products & 0.3924 \\
\hline Manufacture of Furniture & 0.7616 \\
\hline Manufacture of Paper and Paper Products & 0.3239 \\
\hline Printing, Reproduction of Recording Media & 0.5172 \\
\hline Manufacture of Culture, Education, Handicraft, Fine Arts, Sports and Entertainment Articles & 0.9220 \\
\hline Processing of Petroleum, Coking, Processing of Nuclear Fuel & 0.4807 \\
\hline Manufacture of Raw Chemical Materials and Chemical Products & 0.3110 \\
\hline Manufacture of Medicines & 0.3302 \\
\hline Manufacture of Chemical Fibers & 0.8627 \\
\hline Manufacture of Rubber and Plastics & 0.3804 \\
\hline Manufacture of Non-metallic Mineral Products & 0.2258 \\
\hline Smelting and Pressing of Ferrous Metals & 0.4934 \\
\hline Smelting and Pressing of Nonferrous Metals & 0.6144 \\
\hline Manufacture of Metal Products & 0.3816 \\
\hline Manufacture of General Purpose Machinery & 0.3704 \\
\hline Manufacture of Special Purpose Machinery & 0.5625 \\
\hline Transport Equipment & 0.7588 \\
\hline Manufacture of Electrical Machinery and Equipment & 0.6588 \\
\hline Manufacture of Communication Equipment, Computers and Other Electronic Equipment & 0.8119 \\
\hline Manufacture of Measuring Instruments and Machinery for Cultural Activity and Office Work & 0.5563 \\
\hline
\end{tabular}

As it can be seen from Table 3, the highest mean value for the Manufacture of Culture, Education, Handicraft, Fine Arts, Sports and Entertainment Articles was 0.9220. Manufacture of Non-metallic Mineral Products has the lowest mean value of only 0.2258. In addition, the mean value of GTFP of Manufacture of Foods, Liquor, Beverage and Refined Tea, Manufacture of Textile, Manufacture of Paper and Paper Products, Printing, Reproduction of Recording Media, Processing of Petroleum, Coking, Processing of Nuclear Fuel, Manufacture of Raw Chemical Materials and Chemical Products, Manufacture of Medicines, Manufacture of Rubber and Plastics, Smelting and Pressing of Ferrous Metals, Manufacture of Metal Products and Manufacture of General Purpose Machinery are less than 0.5000. This means that the overall development level of GTFP in Chongqing's manufacturing industry is relatively low, and there will still be room for improvement in the future. 


\section{Measurement Model, Variable Setting and Data Description}

\subsection{Econometric Model}

In measuring the total factor productivity of the manufacturing industry, the SBM Directional Distance Function selects the input and output indicators that the decision unit can control, and does not consider other uncontrollable factors. However, these factors are often the major cause of differences in the GTFP. Therefore, this paper empirically analyzes the GTFP of the manufacturing industry, mainly based on the assumptions of the previous hypothesis, setting relevant variables and econometric models. According to the above, the GTFP based on the SBM Directional Distance Function is $0-1$, which is a restricted dependent variable. We use the panel Tobit model to process it. The specific model is set as follows:

$$
\begin{aligned}
& G_{T F P} P_{i t}=\alpha_{0}+\alpha_{1} I A_{i t}+\alpha_{2} F D I_{i t}+\alpha_{3} L A Q_{i t}+\alpha_{4} R \& D_{i t}+\alpha_{5} A S S_{i t} \\
& +\alpha_{6} A L R_{i t}+\alpha_{7} P R O_{i t}+\varepsilon_{i t} \\
& G T F P_{i t}=\left\{\begin{array}{l}
G T F P_{i t}^{*}, \text { if } 0<G T F P_{i t} \leq 1 \\
0, \text { if } \operatorname{GTFP}_{i t}>1 \\
G T F P_{i t}, \text { if } G T F P_{i t}<0
\end{array}\right.
\end{aligned}
$$

In formula (5), GTFP it is a latent variable and $G T F P_{i t}$ is an observed value of the dependent variable. The definitions of related indicators below are also the same. The core explanatory variables are industrial agglomeration $(I A)$ and foreign direct investment ( FDI ). The control variables are 5 indicators: labor quality ( $L A Q)$, research and development $(R \& D)$, asset size $(A S S)$, asset liability ratio $(A L R)$ and profitability ( $P R O)$. The subscripts $i$ and $t$ denote the i-th industry and the t-year respectively. Based on formula (5), the intersection term of industrial agglomerations $I A$ and FDI is further introduced, and the combined effects of the two are analyzed:

$$
\begin{aligned}
G T F P_{i t}= & \alpha_{0}+\alpha_{1} I A_{i t}+\alpha_{2} F D I_{i t}+\alpha_{3} I A_{i t} \times F D I_{i t}+\alpha_{4} L A Q_{i t}+\alpha_{5} R \& D_{i t} \\
& +\alpha_{6} A S S_{i t}+\alpha_{7} A L R_{i t}+\alpha_{8} P R O_{i t}+\varepsilon_{i t}
\end{aligned}
$$

In formula (6), $I A \times F D I$ represents the intersection of $I A$ and $F D I$ and is used to analyze the combined effects of both on GTFP. In addition, $\alpha_{0}$ is a constant term and $\alpha_{q}(q=1,2, \cdots, 5)$ are regression coefficients. $\varepsilon$ represents the residual item.

In order to ensure the robustness of the research conclusion, we use GTFP as the explanatory variable and $I A$ and $F D I$ as explanatory variables to construct the general panel model:

$$
\begin{aligned}
G_{T F P}= & \beta_{0}+\beta_{1} I A_{i t}+\beta_{2} F D I_{i t}+\beta_{3} L A Q_{i t}+\beta_{4} R \& D_{i t}+\beta_{5} A S S_{i t} \\
& +\beta_{6} A L R_{i t}+\beta_{7} P R O_{i t}+\mu_{i t} \\
G T F P_{i t}= & \beta_{0}+\beta_{1} I A_{i t}+\beta_{2} F D I_{i t}+\beta_{3} I A_{i t} \times F D I_{i t}+\beta_{4} L A Q_{i t}+\beta_{5} R \& D_{i t} \\
& +\beta_{6} A S S_{i t}+\beta_{7} A L R_{i t}+\beta_{8} P R O_{i t}+\mu_{i t}
\end{aligned}
$$

In formula (7) and formula (8), $\beta_{0}$ is a constant term and $\beta_{p}(p=1,2, \cdots, 8)$ are regression coefficients. $\mu$ is a residual item. Other unexplained variables and symbolic meanings are identical in the same formula (5) and formula (6).

\subsection{Variables and Data Description}

Based on the empirical models, this section mainly refers to the practice of classic literature in the field to screen the measurement methods and indicators of specific variables. The specific description is as follows: (i) The explained variable. The explained variable is mainly derived from the GTP measured by the SBM Directional Distance Function. (ii)Core Independent Variable. Firstly, the industrial agglomeration ( $I A$ ) will be described. With the development of the theory of industrial agglomeration, the methods for measuring the level of industrial agglomeration have also been continuously developed and improved, from the Industrial Share 
Indicators to Industry Concentration Indicators, Herfindahl Index, Lorentz Curve, and Spatial Gini Coefficient Method, etc. The agglomeration index method, more and more new measurement indicators are used to measure the industrial agglomeration. In order to fully reflect the characteristics of Chongqing's industrial agglomeration, this paper mainly uses the concept of location entropy to measure the degree of agglomeration of various manufacturing industries in Chongqing. Location entropy, also known as the local specialization index, is an indicator that measures the degree of local industry specialization. Its calculation formula is: $A I_{i j}=\left(I_{i j} / I_{j}\right) /\left(I_{i} / I\right)$. Among them, $I_{i j}$ denotes the output index of industry $i$ in region $j, I_{j}$ denotes the output index of all industries in $j$ region, $I_{i}$ denotes the output index of the $i$ industry in all regions of the country, and $I$ denotes the output indicators of all regions and all industries in the country. Secondly, foreign direct investment (FDI) is described. FDI helps to strengthen the cooperation and exchange between local and foreign companies, and promotes the production efficiency of the industry. A large number of foreign capitals will help the transformation of domestic corporate governance concepts and incentives, so that the ownership structure of high-tech enterprises will exhibit diversified features. FDI has greatly improved the overflow of technical knowledge and improved the allocation of R\&D resources in the industry. This article uses the manufacturing industry to use foreign capital to reflect FDI. (iii)Control Variables. We will explain each one by one according to the order of control variables designed by the models. Labor quality ( $L A Q$ ). Labors is an important factor in improving the productivity of the manufacturing industry. It can reflect the level of education, work skills, and health of labors. Scholars have pointed out that basic education, knowledge and skills, and accumulation of work experience are effective ways to promote the increase in the quality of the workforce and increase labor productivity [28]. The quality of the labor force is crucial to the economic growth of a country. The upgrading of the labor force quality not only provides a large number of outstanding talents for the manufacturing enterprises in Chongqing, but also plays an invaluable role in improving the overall efficiency of the industry. So far, Chongqing Statistics Bureau has not compiled data on the number of years of employee education in various manufacturing industries. In order to be able to explore the influence of the quality of the workforce on total factor productivity from a more microscopic level, the number of scientific research personnel in various industries of the manufacturing industry is used in this paper. The proportion of employees to measure labor quality indicators. Research and development $(R \& D)$. At present, there are $R \& D$ expenditures that are commonly used by the academic community for $R \& D$ input indicators $[29,30,31]$, patent applications [32, 33, 34], Innovating product sales income[35, 36]. This article mainly uses the ratio of the internal expenditure of Chongqing's manufacturing R\&D to the total industrial output value as a measure. Asset size ( $A S S$ ).With the continuous deepening of the study of economies of scale, the scale of the manufacturing industry has gradually attracted the attention of scholars. Under normal circumstances, small-scale enterprises lack the driving force for innovation, while large-scale enterprises have perfect equipment and conditions, strong capital strength, and they have an advantage in technological innovation. The willingness of enterprises to carry out technological innovation is stronger, which is more conducive to the improvement of production efficiency. Some scholars also believe that the scale of the company has been expanded to a certain extent, the organizational structure and rules and regulations of the company are difficult to change, the business management and management processes are more complicated, and the efficiency of the company is reduced, resulting in uneconomical scale [37]. In this paper, the net value of fixed assets is used to measure the asset size of Chongqing's manufacturing industry. Asset liability ratio $(A L R)$. The asset liability ratio is an important indicator of the capital structure. A reasonable asset liability ratio is conducive to standardizing corporate behavior, improving corporate operating performance, and further increasing corporate value. On the contrary, a poor asset liability ratio will lead to low corporate operating performance and declining corporate value, which will lead to a decline in green total factor productivity. That is, the asset liability ratio will produce both financial leverage and risk. Therefore, the introduction of asset liability ratio analysis of GTFP is necessary. 
This indicator is directly obtained from the economic reports released by the Chongqing's manufacturing industry. Finally, we explain to profitability $(P R O)$. The profitability is an indicator to reflect the overall benefit level of the industry or enterprise. In the process of production, the manufacturing industry must invest sufficient financial, human and material resources to ensure the smooth progress of the production activities. At the same time, the products produced can have a good demand market so that the enterprises can gain profit. Profits provide sufficient $R \& D$ funds for enterprises to carry out environmental technological innovation and research and development of clean products. According to the general practice, we select the profit growth rate of manufacturing industry as an index to measure profitability.

\subsection{Data Description and Processing}

The data used in this empirical study are mainly derived from the Statistical Yearbook of China's Industrial Economy and the Chongqing Statistical Yearbook. The sample covers the period 1999-2015. We take the 1999 as the base period and use the gross domestic product index to translate nominal data into actual data. The statistics of the processed variables are shown in Table 4.

Table 4. Descriptive Statistics of Variables

\begin{tabular}{cccccc}
\hline Variables & Mean & Min & Max & Std. Dev. & Obs. \\
\hline GTFP & 0.5140 & 0.0256 & 1.0000 & 0.3319 & 0.5140 \\
$I A$ & 0.9049 & 0.0026 & 6.0078 & 1.0011 & 0.9049 \\
FDI & 0.3425 & 0.0000 & 8.9442 & 0.9009 & 0.3425 \\
LAQ & 0.0380 & 0.0000 & 0.5976 & 0.0763 & 0.0380 \\
R\&D & 0.0090 & 0.0000 & 0.9658 & 0.0468 & 0.0090 \\
LnASS & 11.3187 & 5.0299 & 15.1052 & 1.7654 & 11.3187 \\
ALR & 0.5858 & 0.1550 & 1.1090 & 0.1303 & 0.5858 \\
$P R O$ & 7.1057 & 0.0020 & 2466.3860 & 115.3389 & 7.1057 \\
\hline
\end{tabular}

\section{Empirical Results and Discussion}

According to the empirical model designed above, this paper uses STATA 14.0 to estimate the correlation coefficient. Table 5 and Table 6 reports the specific measurement results of the model. In the following, detailed, analysis will be carried out based on the previous measurement model and variables.

\subsection{Analysis of Regression Results under Panel Tobit Model}

Firstly, the panel Tobit model measurement results are parsed. Table 5 shows the effect of industrial agglomeration and FDI on GTFP. From the core interpretation of variable coefficient estimation results, model (1) to model (7) list the effect of industrial agglomeration and FDI on GTFP. At a 1\% level of significance, industrial agglomeration has a positive effect on GTFP, with regression coefficients of $0.1064,0.1067,0.1109$, $0.1111,0.1546,0.1583$, and 0.1581 respectively. It shows that agglomeration of the manufacturing industry is conducive to the growth of green total factor productivity. FDI has a inhibitory effect on GTFP, and the regression coefficients are $-0.0341,-0.0331,-0.0355,-0.0354,-0.0239,-0.0245$ and -0.0244 respectively, but the results are not statistically significant. As Walter and Ugelow (1979) put forward the hypothesis of a "pollution haven" [38], when developed countries invest in developing countries, they mainly focus on the cheap labor, rich resources, and loose environmental supervision of developing countries. The industries in developed countries that have relatively serious pollution and relatively high energy consumption have been transferred to developing countries, and they have obtained substantial capital gains, which has seriously damaged the ecological environment in developing countries. Judging from the current situation of FDI in Chongqing, the FDI is mainly concentrated in resource-intensive industries, causing environmental pollution and waste of resources, while investment in technology-intensive industries is relatively small, making it 
difficult for Chongqing's manufacturing industries to master the core technologies and advanced management concepts has made FDI produce an inhibitory effect on the GTFP. At the same time, there is a competitive relationship between foreign enterprises and local enterprises, so foreign enterprises will try to prevent the production of technology spillovers, which, to a certain extent, reduces the investment scale of foreign enterprises for technology intensive manufacturing enterprises. This makes it difficult for Chongqing's manufacturing industry to grasp the core technology of foreign countries, and the lack of technological innovation capability. Model (2) to model (7) gradually introduced industrial agglomeration and FDI interaction items. The coefficient estimation results show that the coefficients of green total factor productivity of the two interaction items are $-0.0010,-0.0006,-0.0007,-0.0003,0.00002$ and -0.0001 respectively, but the results are not statistically significant. On the whole, FDI counteracts the role of industrial agglomeration in promoting GTFP.

Table 5. Panel Tobit Model Regression Results

\begin{tabular}{|c|c|c|c|c|c|c|c|}
\hline & (1) & (2) & (3) & (4) & (5) & (6) & (7) \\
\hline \multirow[t]{2}{*}{ Constant } & $0.4367 * * *$ & $0.4366^{* * *}$ & $0.4143 * * *$ & $0.4136 * * *$ & $1.2726 * * *$ & $1.2106 * * *$ & $1.2132 * * *$ \\
\hline & $(8.22)$ & $(8.20)$ & $(7.76)$ & $(7.75)$ & $(9.89)$ & $(8.98)$ & $(9.01)$ \\
\hline \multirow[t]{2}{*}{$I A$} & $0.1064 * * *$ & $0.1067 * * *$ & $0.1109 * * *$ & $0.1111 * * *$ & $0.1546 * * *$ & $0.1583 * * *$ & $0.1581 * * *$ \\
\hline & $(8.72)$ & $(8.35)$ & $(8.75)$ & $(8.76)$ & (11.30) & (11.43) & (11.43) \\
\hline \multirow[t]{2}{*}{$F D I$} & $-0.0341 *$ & -0.0331 & -0.0355 & -0.0354 & -0.0239 & -0.0245 & -0.0244 \\
\hline & $(-1.82)$ & $(-1.46)$ & $(-1.58)$ & $(-1.58)$ & $(-1.10)$ & $(-1.13)$ & $(-1.13)$ \\
\hline \multirow[t]{2}{*}{$I A \times F D I$} & & -0.0010 & -0.0006 & -0.0007 & -0.0003 & 0.00002 & -0.0001 \\
\hline & & $(-0.07)$ & $(-0.04)$ & $(-0.05)$ & $(-0.02)$ & $(0.00)$ & $(-0.01)$ \\
\hline \multirow[t]{2}{*}{$L A Q$} & & & $0.5813 * * *$ & $0.5847 * * *$ & $0.6106^{* * *}$ & $0.5918 * * *$ & $0.5634 * * *$ \\
\hline & & & $(3.41)$ & $(3.43)$ & $(3.79)$ & (3.67) & (3.44) \\
\hline \multirow[t]{2}{*}{$R \& D$} & & & & $0.1172 * * *$ & 0.0723 & 0.0348 & 0.0353 \\
\hline & & & & (3.43) & $(0.39)$ & $(0.19)$ & $(0.19)$ \\
\hline \multirow[t]{2}{*}{ LnASS } & & & & & $-0.0804 * * *$ & $-0.0844 * * *$ & $-0.0843 * * *$ \\
\hline & & & & & $(-7.10)$ & $(-7.25)$ & $(-7.26)$ \\
\hline \multirow[t]{2}{*}{$A L R$} & & & & & & 0.1472 & 0.1442 \\
\hline & & & & & & $(1.56)$ & (1.53) \\
\hline \multirow[t]{2}{*}{ PRO } & & & & & & & 0.0001 \\
\hline & & & & & & & $(0.96)$ \\
\hline Log likelihood & 93.45 & 93.45 & 99.20 & 99.39 & 121.85 & 123.06 & 123.52 \\
\hline Wald chi2(18) & $604.88 * * *$ & $604.89 * * *$ & $632.95 * * *$ & $633.75 * * *$ & $726.41 * * *$ & $732.55 * * *$ & $734.99 * * *$ \\
\hline Obs. & 459 & 459 & 459 & 459 & 459 & 459 & 459 \\
\hline
\end{tabular}

Note: T-statistics are reported in parentheses. * for $10 \%$ level significant, $* *$ for $5 \%$ level significant, *** for $1 \%$ level significant.

Further observe the regression results. Models (3) to model (7) gradually introduce control variables to regress to the model. First of all, at the $1 \%$ level of significance, the labor quality has a positive impact on GTFP. The regression coefficients are $0.5813,0.5847,0.6106,0.5918$, and 0.5634 respectively. Therefore, the quality of the workforce can effectively increase the GTFP. Secondly, the R\&D investment in science and technology has always had a positive impact on green total factor productivity. With the continuous increase in R\&D investment in science and technology, the growth effect of GTFP will be even more significant. In addition, the asset liability ratio and profitability can all increase the GTFP. From this, we can see that profitability is crucial to the improvement of GTFP. This means that creating a good economic development environment and atmosphere for the development of the manufacturing industry will help increase the profitability of the manufacturing industry, and thus provide sufficient funds for the R\&D of manufacturing 
companies' science and technology, and ultimately increase the GTFP. Finally, the model (5) to the model (7) showed that the regression coefficients were $-0.0804,-0.0844$ and -0.0843 under the significant level of $1 \%$, indicating that the industry size had an inhibitory effect on the GTFP. Therefore, the large scale of manufacturing industry is not conducive to the promotion of GTFP. Therefore, under the constraint of resources, the overlarge manufacturing industry can easily lead to a decrease in the production management efficiency of manufacturing enterprises. Policy makers can only control the scale of the manufacturing industry in a modest manner, or, in the process of industrial scale expansion, formulate environmental protection measures to strictly limit the equipment, technology, and pollution discharge standards used in the industry's production, to improve the industry's production efficiency.

\subsection{Robustness Test}

The results of the panel Tobit model are analyzed in the foregoing. In order to ensure the robustness of the conclusion of this study, we apply the panel model to further regression. The results of the specific measurement are shown in Table 6. Consistent with the foregoing, we analyze the results.

Table 6. Panel Model Regression Results

\begin{tabular}{|c|c|c|c|c|c|c|c|}
\hline & (8) & (9) & (10) & (11) & (12) & (13) & (14) \\
\hline Constant & $\begin{array}{c}0.4295^{* * *} \\
(11.29)\end{array}$ & $\begin{array}{c}0.4294 * * * \\
(11.26)\end{array}$ & $\begin{array}{c}0.4060 * * * \\
(10.59)\end{array}$ & $\begin{array}{c}0.4053^{* * * *} \\
(10.56)\end{array}$ & $\begin{array}{c}1.1543 * * * \\
(7.87)\end{array}$ & $\begin{array}{c}1.0766^{* * *} \\
(6.95)\end{array}$ & $\begin{array}{c}1.0809^{* * * *} \\
(6.97)\end{array}$ \\
\hline$I A$ & $\begin{array}{c}0.1123^{* * * *} \\
(8.85)\end{array}$ & $\begin{array}{c}0.1125^{* * *} \\
(8.48)\end{array}$ & $\begin{array}{c}0.1170^{* * *} \\
(8.89)\end{array}$ & $\begin{array}{c}0.1172^{* * *} \\
(8.89)\end{array}$ & $\begin{array}{c}0.1525^{* * * *} \\
(10.58)\end{array}$ & $\begin{array}{c}0.1561 * * * \\
(10.71)\end{array}$ & $\begin{array}{c}0.1559^{* * *} \\
(10.69)\end{array}$ \\
\hline FDI & $\begin{array}{l}-0.0286 \\
(-1.49)\end{array}$ & $\begin{array}{l}-0.0281 \\
(-1.21)\end{array}$ & $\begin{array}{l}-0.0303 \\
(-1.32)\end{array}$ & $\begin{array}{l}-0.0302 \\
(-1.31)\end{array}$ & $\begin{array}{l}-0.0208 \\
(-0.93)\end{array}$ & $\begin{array}{l}-0.0211 \\
(-0.95)\end{array}$ & $\begin{array}{l}-0.0211 \\
(-0.94)\end{array}$ \\
\hline$I A \times F D I$ & & $\begin{array}{l}-0.0005 \\
(-0.04)\end{array}$ & $\begin{array}{l}-0.0003 \\
(-0.02)\end{array}$ & $\begin{array}{l}-0.0004 \\
(-0.03)\end{array}$ & $\begin{array}{l}0.0002 \\
(0.01)\end{array}$ & $\begin{array}{l}0.0002 \\
(0.02)\end{array}$ & $\begin{array}{l}0.0002 \\
(0.01)\end{array}$ \\
\hline$L A Q$ & & & $\begin{array}{c}0.6077 * * * \\
(3.37)\end{array}$ & $\begin{array}{c}0.6110^{* * * *} \\
(3.38)\end{array}$ & $\begin{array}{c}0.6022 * * * \\
(3.44)\end{array}$ & $\begin{array}{c}0.5892 * * * \\
(3.37)\end{array}$ & $\begin{array}{c}0.5613^{* * * *} \\
(3.16)\end{array}$ \\
\hline$R \& D$ & & & & $\begin{array}{c}0.1023 \\
(0.53)\end{array}$ & $\begin{array}{c}0.0673 \\
(0.36)\end{array}$ & $\begin{array}{c}0.0283 \\
(0.15)\end{array}$ & $\begin{array}{c}0.0288 \\
(0.15)\end{array}$ \\
\hline LnASS & & & & & $\begin{array}{c}-0.0698^{* * *} \\
(-5.28)\end{array}$ & $\begin{array}{c}-0.0726^{* * *} \\
(-5.45)\end{array}$ & $\begin{array}{c}-0.0727 * * * \\
(-5.46)\end{array}$ \\
\hline$A L R$ & & & & & & $\begin{array}{c}0.1518 \\
(1.53)\end{array}$ & $\begin{array}{c}0.1485 \\
(1.49)\end{array}$ \\
\hline PRO & & & & & & & $\begin{array}{r}0.0001 \\
(0.91)\end{array}$ \\
\hline $\mathrm{R}^{2}$ & 0.59 & 0.59 & 0.59 & 0.60 & 0.62 & 0.62 & 0.62 \\
\hline F-statistics & $30.68^{* * * *}$ & $30.68 * * *$ & $30.68^{* * *}$ & $28.96^{* * *}$ & $30.72 * * *$ & $29.58^{* * *}$ & $28.37^{* * *}$ \\
\hline Obs. & 459 & 459 & 459 & 459 & 459 & 459 & 459 \\
\hline
\end{tabular}

Note: T-statistics are reported in parentheses. * for $10 \%$ level significant, ** for $5 \%$ level significant, *** for $1 \%$ level significant.

As shown in the Table 6, model (8) lists the effect of industrial agglomeration and FDI on GTFP. From the measurement results, at a $1 \%$ level of significance, industrial agglomeration has a positive effect on GTFP, with a regression coefficient of 0.1123 . It shows that agglomeration of the manufacturing industry is conducive to the growth of GTFP. Further, FDI has an inhibitory effect on GTFP with a regression coefficient of -0.0286 , but this result is not statistically significant. Therefore, FDI has hindered the growth of the GTFP. With the absolute advantages of mature technology, foreigners can use the cheap labor in Chongqing to reduce their production costs and obtain a more substantial return on capital. Similarly, models (9) to models (14) can reach similar 
conclusions. Interestingly, model (9) introduced the interaction of industrial agglomeration and FDI. The result shows that under the significant level of $1 \%$, industrial agglomeration had a positive impact on GTFP, the regression coefficient is 0.1125 , while FDI had an inhibitory effect on GTFP, and the regression coefficient is -0.0281. At the same time, the coefficient of interaction between the two factors on green total factor productivity is -0.0005 , indicating that FDI counteracts the role of industrial agglomeration in promoting GTFP. Therefore, industrial agglomeration will help to improve the GTFP of Chongqing's manufacturing industry, but FDI hinders the growth of GTFP in Chongqing's manufacturing industry.

The estimated results of control variable coefficients are basically consistent with the previous conclusions. Model (10) to model (14) gradually introduces control variables to model regression. Firstly, under the $1 \%$ significant level, the labor quality has a positive impact on the GTFP. The regression coefficients of model (10) to model (14) are $0.6077,0.6110,0.6022,0.5892$ and 0.5613 respectively. Therefore, the labor quality is closely related to the productivity level of the manufacturing industry. The accumulation of human capital produced by the workers will help to improve the overall labor quality in the manufacturing industry, improve the labor skills and labor productivity, thus reduce the cost of production and reduce the idle and waste of the resources for the enterprises. Finally, it effectively improves the GTFP. Secondly, the R\&D investment has a positive impact on the GTFP, and the regression coefficients of the model (11) to model (14) are 0.1023, 0.0673, 0.0283 and 0.0288 respectively, but the results are not statistically significant. Overall, with the increasing investment in R\&D, the growth of GTFP will also be more significant. In addition, asset liability ratio and profitability can improve the GTFP. Finally, the model (12) to model (14) shows that asset size has an inhibitory effect on GTFP. At the $1 \%$ significant level, the regression coefficients of asset size are $-0.0698,-0.0726$ and -0.0727 respectively. The above results mean that the scale effect of the manufacturing industry in Chongqing is not significant, and that the industry is too large, and it is not conducive to the improvement of GTFP. The above results further validate the previous conclusion that the "pollution haven" is established.

\section{Conclusions}

Manufacturing industry plays an extremely important role in the process of economic development. Chongqing's economic growth in recent years is inseparable from the contribution of manufacturing industry. However, there are high energy consumption, high pollution, and low efficiency in the development of the manufacturing industry in Chongqing. This extensive growth mode leads to a large amount of resource consumption and serious environmental pollution. This paper explores the impact mechanism of industrial agglomeration and foreign direct investment(FDI) on the green total factor productivity(GTFP) of manufacturing industry, constructs a GTFP evaluation index system for manufacturing industry, selects the labor, capital, energy expected input and undesirable output of Chongqing's manufacturing industry. Based on the data, the SBM Directional Distance Function was used to measure the GTFP of 27 manufacturing industries in Chongqing from 1999 to 2015. Then, we use the panel Tobit model to study the impact of industrial agglomeration and FDI on GTFP. The study found that the higher the level of industrial agglomeration, the more conducive to improving the GTFP. FDI will impede the GTFP to a certain extent, and its technology spillover effect is not significant. At the same time, FDI offsets the role of industrial agglomeration in promoting GTFP, which is mainly due to the negative moderating effect of FDI on industrial agglomeration. Therefore, according to Chongqing's experience, the "pollution haven" is established.

The policy implications of the above conclusions are as follows: the policy makers should optimize the layout of the manufacturing industry, encourage the concentration of manufacturing industries, focus on the development of high-tech and high-value-added enterprises, and coordinate the development of high-tech and clean industries. By optimizing the structural ratio between labor-intensive industries and high-tech and capital-intensive industries, the high-tech and capital-intensive industries are fostered into the main force of 
industrial clusters, alleviate the problems of serious environmental pollution, high energy consumption and low output caused by resource intensive industries and labor-intensive industrial agglomeration. At the same time, reducing the dependence on foreign capital. The attraction of foreign investment in the process of industrial agglomeration is no longer a favorable factor for the development of the manufacturing industry. It is obvious that there are many disadvantages in the development of manufacturing industry by relying solely on foreign technology. This means that enhancing the ability of independent innovation is the reliable way to effectively enhance the GTFP of manufacturing industry.

\section{References}

1. Hu, J.F.; Wang, Z.; Lian, Y.H.; Huang, Q.H. Environmental Regulation, Foreign Direct Investment and Green Technological Progress-Evidence from Chinese Manufacturing Industries[J]. International Journal of Environmental Research and Public Health, 2018, 15:221-234.

2. Chung, Y.H.; Fare, R.; Grosskopf, S. Productivity and Undesirable Outputs: A Directional Distance Function Approach[J]. Journal of Environmental Management, 1995, 51: 229-240.

3. Mitra, A.; Sato, H. Agglomeration Economies in Japan: Technical Efficiency, Growth and Unemployment [J]. Review of Urban \& Regional Development Studies, 2007, 19:197-209.

4. Lee, Y.; Chyi, Y.L.; Lin, E.S.; Wu, S.Y. Do Local Industrial Agglomeration and Foreign Direct Investment to China Enhance the Productivity of Taiwanese Firms?[J]. Journal of International Trade \& Economic Development, 2013, 22:839-865.

5. Duranton, G.; Puga, D. Nursery Cities: Urban Diversity, Process Innovation, and the Life Cycle of Products[J]. American Economic Review, 2001, 91:1454-1477.

6. Storper, M.; Venables, A.J. Face-To-Face Contact And The Urban Economy[J]. Journal of Economic Geography, 2004, 4:351-370.

7. Henderson, J.V. Marshall's Scale Economies[J]. Journal of Urban Economics, 2003, 53:1-28.

8. Barrell, R.; Pain, N. Domestic Institutions, Agglomerations and Foreign Direct Investment in Europe[J]. European Economic Review, 2004, 43: 925-934.

9. Blomström, M.; Kokko, A. Multinational Corporations and Spillovers[J]. Journal of Economic Surveys, 1998, 12:247-277.

10. Kugler, M. Spillovers from Foreign Direct Investment: Within or Between Industries?[J]. Journal of Development Economics, 2006, 80:444-477.

11. Z, W.; Liu, L.; Zhao, T. The Contribution of Outward Direct Investment to Productivity Changes Within China, 1991-2007[J]. Journal of International Management, 2010, 16:121-130.

12. Hiau, L.K. Local Intermediate Inputs and the Shared Supplier Spillovers of Foreign Direct Investment[J]. Journal of Development Economics, 2014, 112:56-71.

13. Antweiler, W.; Copeland, B.R.; Taylor, M.S. Is Free Trade Good for the Environment?[R]. NBER Working Paper, 1998, No.6707.

14. List, J.A; Co, C.Y. The Effects of Environmental Regulations on Foreign Direct Investment[J]. Journal of Environmental Economics \& Management, 2000, 40:1-20.

15. Copeland, B.R; Taylor, M.S. Trade, Growth, and the Environment[J]. Journal of Economic Literature, 2004, 42:7-71.

16. Zugravu-Soilita, N. How does Foreign Direct Investment Affect Pollution? Toward a Better Understanding of the Direct and Conditional Effects[J]. Environmental \& Resource Economics, 2017, 66:293-338.

17. Esty, D.C.; Geradin, D. Market Access, Competitiveness, and Harmonization: Environmental Protection in Regional Trade Agreements[J]. Social Science Electronic Publishing, 1997, 21:265-336. 
18. Chambers, R.G.; Färe, R.; Grosskopf, S. Productivity Growth in APEC Countries [J]. Pacific Economic Review, 1996, 1:181-190.

19. Fare, R.; Grosskopf, S.; Norris, M.; Zhang, Z.Y. Productivity Growth, Technical Progress, and Efficiency Change in Industrialized Countries[J]. American Economic Review, 1994, 84:66-83.

20. Kaneko, S.; Managi, S. Environmental Productivity in China[J]. Economics Bulletin, 2004, 17:1-10.

21. Ramanathan, R. An Analysis of Energy Consumption and Carbon Dioxide Emissions in Countries of the Middle East and North Africa[J]. Energy, 2005, 30: 2831-2842.

22. Watanabe, M.; Tanaka, K. Efficiency Analysis of Chinese Industry: A Directional Distance Function Approach [J]. Energy Policy, 2007, 35:6323-6331.

23. Feng, G.H.; Serletis, A. Undesirable Outputs and a Primal Divisia Productivity Index Based on the Directional Output Distance Function[J]. Journal of Econometrics, 2014, 183:135-146.

24. Zofío, J.L.; Prieto, A.M. Environmental Efficiency and Regulatory Standards: The Case of CO2 Emissions from OECD Industries[J]. Resource \& Energy Economics, 2001, 23:63-83.

25. Jeon B.M.; Sickles, R.C. The Role of Environmental Factors in Growth Accounting[J]. Journal of Applied Econometrics, 2004, 19:567-591.

26. Tone, K. A Slacks-based Measure of Super-efficiency in Data Envelopment Analysis[J]. European Journal of Operational Research, 2003, 143:32-41.

27. Chambers, R.G.; Chung, Y.; Färe, R. Benefit and Distance Functions[J]. Journal of Economic Theory, 1996, 70:407-419.

28. Autor, D.H.; Levy, F.; Murnane, R.J. The Skill Content of Recent Technological Change: An Empirical Exploration[J]. Quarterly Journal of Economics, 2001, 118:1279-1333.

29. Aghion, P.; Howitt, P. A Model of Growth Through Creative Destruction[J]. Econometrica, 1992, 60:323-351.

30. Eaton, J.; Kortum, S. International Technology Diffusion: Theory and Measurement[J]. International Economic Review, 1999, 40:537-570.

31. Bosković, S.; Haracić, M.; Basić, V. Measuring the Economic Benefits from R\&D: Improvements in the MMI Model of the United Kingdom National Measurement System[J]. Research Policy, 2003, 32:991-1002.

32. Griliches, Z. Patent Statistics as Economic Indicators: A Survey[J]. Journal of Economic Literature, 1990, 28:1661-1707.

33. Jaffe, A.B.; Palmer, K. Environmental Regulation and Innovation: A Panel Data Study[J]. Review of Economics \& Statistics, 1997, 79:610-619.

34. Cuddington, J.T.; Moss, D.L. Technological Change, Depletion, and the U.S. Petroleum Industry[J]. American Economic Review, 2001, 91:1135-1148.

35. Zweimüller, J.; Brunner, J.K. Innovation and Growth with Rich and Poor Consumers[J]. Metroeconomica, 2005, 56:233-262.

36. Giulioni, G. Endogenous Recessions: The Creative Destruction Effect of Final Product Novelty[J]. Economic Modelling, 2010, 27:516-522.

37. Afonso, A.; Fernandes, S. Assessing and Explaining the Relative Efficiency of Local Government[J]. The Journal of Socio-Economics, 2008, 37:1946-1979.

38. Walter, I.; Ugelow, J.L. Environmental Policies in Developing Countries[J]. Ambio, 1979, 8:102-109. 